\title{
A finite-strain solid-shell using local Löwdin frames and least-squares strains
}

\author{
P. Areias ${ }^{\mathrm{a}, \mathrm{d}, *}$, C.A. Mota Soares ${ }^{\mathrm{b}}$, T. Rabczuk ${ }^{\mathrm{c}}$, J. Garção $^{\mathrm{d}, \mathrm{a}}$ \\ ${ }^{a}$ Department of Physics, University of Évora, Colégio Luís António Verney, Rua Romão Ramalho, 59, 7002-554 Évora, Portugal \\ ${ }^{\mathrm{b}}$ IDMEC, Instituto Superior Técnico, Universidade de Lisboa, 1049-001 Lisboa, Portugal \\ ${ }^{\mathrm{c}}$ Institute of Structural Mechanics, Bauhaus-University Weimar, Marienstraße 15, 99423 Weimar, Germany \\ ${ }^{\mathrm{d}}$ CERIS, Instituto Superior Técnico, Lisboa, Portugal
}

Received 24 May 2016; received in revised form 28 July 2016; accepted 29 July 2016

Available online 5 August 2016

\section{Highlights}

- Finite strain solid-shell element with good distortion insensitivity.

- Shell benchmarking and comparison with established techniques.

- Motion of anisotropic axes by use of Lowdin frames.

- Constitutive framework based on a consistent updated-Lagrangian formulation with smoothed complementarity condition.

- Combination with standard 3D elements avoids additional tasks.

\begin{abstract}
A finite-strain solid-shell element is proposed. It is based on least-squares in-plane assumed strains, assumed natural transverse shear and normal strains. The singular value decomposition (SVD) is used to define local (integration-point) orthogonal frames-ofreference solely from the Jacobian matrix. The complete finite-strain formulation is derived and tested. Assumed strains obtained from least-squares fitting are an alternative to the enhanced-assumed-strain (EAS) formulations and, in contrast with these, the result is an element satisfying the Patch test. There are no additional degrees-of-freedom, as it is the case with the enhancedassumed-strain case, even by means of static condensation. Least-squares fitting produces invariant finite strain elements which are shear-locking free and amenable to be incorporated in large-scale codes. With that goal, we use automatically generated code produced by AceGen and Mathematica. All benchmarks show excellent results, similar to the best available shell and hybrid solid elements with significantly lower computational cost.
\end{abstract}

(c) 2016 Elsevier B.V. All rights reserved.

Keywords: Finite-strain solid-shell; Least-squares; Assumed-strains; Singular value decomposition

\footnotetext{
* Corresponding author at: Department of Physics, University of Évora, Colégio Luís António Verney, Rua Romão Ramalho, 59, $7002-554$ Évora, Portugal. Fax: +351 266745394.

E-mail address: pmaa@uevora.pt (P. Areias).
} 